\title{
Rubén Sánchez Muñoz y SANDRA García Pérez (COORD.) Meditaciones sobre la filosofía de ORTEga, MéXico, Univer- SIDAD VERACRUZANA/TORRES ASOCIADOS, 2016, 153 PP.
}

\section{Autopresentación}

\author{
Rubén Sánchez Muñoz \\ Benemérita Universidad Autónoma de Puebla (México) \\ rubensm_83@hotmail.com \\ Sandra García Pérez \\ Universidad Veracruzana (México) \\ sandrigp@yahoo.con.mx
}

En 2014 se cumplieron 100 años de la publicación de las Meditaciones del Quijote de Ortega. Esta obra no es solamente el primer libro del filósofo de la escuela de Madrid, es además un libro de filosofía en el que encontramos importantes desarrollos de fenomenología. Pensando en el centenario y en el giro que desde hace algunas décadas ha acontecido con la filosofía de Ortega es que nos propusimos escribir una obra en la que pudiéramos destacar algunos de los aspectos más importantes de la filosofía de Ortega y sus relaciones con la fenomenología.

El objetivo era, entonces, repensar la filosofía de Ortega a la luz de la fenomenología de Husserl. ¿Es la filosofía de Ortega una variante de la fenome- 
nología o se puede encontrar en ella desarrollos de la fenomenología? Como es sabido, esta es una de las líneas a las que se ha dedicado Javier San Martín y es una de las directrices del trabajo que nos propusimos realizar en esta obra, y lo hicimos en las meditaciones como lo hiciera Ortega en aquel libro dedicado al Quijote. Meditar era para el filósofo un ejercicio que requería esfuerzo "doloroso e integral" en el que nuestras ideas tienen que ir abriéndose camino en medio de la masa de pensamientos a fin de esclarecer su sentido, esto es, su razón. Así, Ortega llega a afirmar que la "claridad no es vida" (o sea que la vida no es toda ella razón), también llega a sostener en aquel libro que la claridad es la "plenitud de la vida" (que en la razón la vida alcanza su sentido). La claridad, por ello, llega a jugar un lugar importante en el ejercicio de las meditaciones al grado de llegar a ser un imperativo. Esta ya es una de las razones por las cuales Ortega define sus meditaciones como el resultado de un amor intelectual.

Los autores de los ensayos que componen esta obra compartimos la tesis de que Ortega, o bien es un fenomenólogo o, al menos, que es necesario contar con la influencia de Husserl para comprenderlo, esto es, que el encuentro de Ortega con la fenomenología de Husserl le imprimió a su producción filosófica una dirección tal que en algunos escritos de 1913 a 1916 está claramente expuesta esta influencia y en textos posteriores la influencia está implícita. Esto es así debido a que el mismo Ortega creyó haber abandonado la fenomenología; pero desde hace varias décadas los trabajos de Philip W. Silver, Pedro Cerezo, Inman Fox y Javier San Martín, han permitido ver la importancia de la fenomenología trascendental en el surgimiento y despliegue de la razón vital, inclusive en el despliegue de la razón vital a la razón histórica.

Recordando algunos textos que resultan fundamentales para comprender la recepción de Ortega de la fenomenología y las razones por las cuales abandonó el neokantismo, encontramos la reseña que escribió al libro de Hofmann en 1913 "Sobre el concepto de sensación" y, del mismo año, la conferencia que dictó en el IV Congreso de la Asociación Española para el Progreso de las Ciencias sobre "Sensación, construcción e intuición". De 1914 destaca su "Ensayo de estética a manera de prólogo" y las mismas Meditaciones del Quijote, y de 1916 su Sistema de psicología, mismo que apareciera por primera vez en 1979 bajo la edición de Paulino Garagorri. Claro está que la fenomenología de Ortega, o lo que podemos denominar la recepción de la fenomenología por parte de Ortega y su asimilación, no se reduce solo a estos textos, pero sí resultan tex- 
tos fundamentales y muy significativos por el momento histórico en el cual fueron redactados. En 1913 Husserl había publicado el primer libro de Ideas y para junio de ese mismo año, Ortega ya hace referencia a este libro en su conferencia. De alguna manera este es el marco bibliográfico a partir del cual se tejen los distintos ejes temáticos del libro que presentamos ahora.

La obra consta de seis ensayos. El primero de ellos es el de Javier San Martín, "Para una reforma de la filosofía". En este estudio, San Martín muestra la importancia de la fenomenología en el sentido de la reforma de la filosofía que Ortega asumió muy tempranamente. Para ello se vale el autor de la conferencia que Ortega dictó en junio de 1913 en el IV Congreso al que hicimos alusión poco antes. En esta conferencia se deja percibir la importancia que Ortega había dado en ese momento a la intuición, en la que llegó a ver la superación misma de la modernidad. El comienzo de la fenomenología en 1900, tras la publicación de Investigaciones lógicas supuso para Ortega el fin de la modernidad (p. 17). San Martín muestra que esta tesis está presente en Ortega hasta 1929, fecha en la cual piensa en la fenomenología pero ahora como la culminación de la modernidad. Si al principio, en 1913, Ortega sostiene que con el surgimiento de la fenomenología la modernidad llega a su fin y se inicia una nueva época para la filosofía, en 1929 Ortega considera que la fenomenología es ella misma una parte de la modernidad y con ella estaría la modernidad llegando a su culminación. A pesar de esta toma de distancia de Ortega de la fenomenología, San Martín se da a la tarea de mostrar en qué consiste la reforma de la filosofía y la innovación que supone la fenomenología a partir de 1900 (pp. 19-20). Luego de esto San Martín echa mano de un texto de Ortega de junio de 1928: "Max Scheler. Un embriagado de esencias (1874-1928)" en el que Ortega afirma que "La gigantesca innovación entre ese tiempo y el nuestro ha sido la fenomenología de Husserl. De pronto el mundo se cuajó y empezó a rezumar sentido por todos los poros" (cit. p. 26). Pues bien, en la tercera parte del ensayo San Martín profundiza en la renovación de la filosofía remitiéndose a la superación del carácter representacionalista del conocimiento en la modernidad. Ortega pudo ver bien que en la fenomenología ya no había una mediación en el conocimiento de las cosas sino "una donación directa de las cosas en la intuición" (p. 26). En la intuición podemos encontrar la superación de la filosofía representacionalista de la modernidad, lo que viene a ser la superación del positivismo imperante -el que sigue siendo "la filosofía más universal en el tiempo presente ( $p$. 
21) - y el neokantismo. La superación del positivismo implica el descubrimiento del sentido. Pero, ¿qué es el sentido? San Martín anota que "El sentido es... el ser que se me da de las cosas, un estilo de ser con el que yo cuento en mi inserción en el mundo, en el que siempre estoy actuando" (pp. 28-29). Al final de su ensayo San Martín medita sobre la renovación de la filosofía práctica que no está tan clara o tan desarrollada en Ortega; enfatiza en lo importante que son las lecciones de Husserl sobre la ética expuestas en sus lecciones de 1920 y 1924 y que el mismo Husserl no publicó, y por ello desconocidas por Ortega. El otro aspecto es que Scheler, quien sí dedicó importantes trabajos a la ética, tuvo una vida "sometida a fuertes bandazos que le pudieron restar autoridad intelectual-académica" (p. 31). Aunque Ortega promete desarrollar una ética y pueden encontrarse vestigios de ella en algunos de sus textos, lo cierto es que no escribió ninguna obra dedicada a la materia y esta ética es la que San Martín echa de menos en esta reforma de la filosofía práctica.

El segundo ensayo es de Eduardo González Di Pierro, quien desarrolla la "Presencia de la fenomenología en las Meditaciones del Quijote de Ortega y Gasset". En él, el autor muestra el influjo que la fenomenología de Husserl tuvo en Ortega y el conocimiento de éste del primer libro de las Ideas pasando por las Investigaciones lógicas. Especial importancia cobra el concepto de constitución mismo que ya aparece en la reseña al libro de Hofmann de 1913 y en el cual, a propósito, aparece también la traducción de Erlebnis como vivencia ( $p$. 38). Pero en este ensayo también encontramos señalamientos importantes en los que el autor alcanza a mostrar cómo Ortega se quedó a medio camino de una comprensión completa de la fenomenología (p. 40), por un lado reduciendo la fenomenología a una "descripción pura de esencias", siendo que no es propio de la fenomenología el ser descripción de esencias. Otro tanto ocurre con el concepto de fenómeno que, como dice González Di Pierro, "si bien al inicio parece comprender plenamente como diferente, desde luego, de la acepción kantiana, luego reduce a apariencia, remitiéndonos a la etimología clásica de fainómenon, lo cual, como sabemos, no es compartido por el fundador de la fenomenología". Pues como sabemos el fenómeno en Husserl "no agota su ser en su carácter de apariencia" (p. 38). En palabras del autor ello se debió a varias razones. Primero, la lectura temprana de Ideas I que Ortega creyó haber comprendido; segundo, la visión estática de la fenomenología contenida en Ideas I, misma que sería completada después por Husserl con una visión genética; la 
tercera razón fue precisamente que por estos años Ortega ya maduraba algunas ideas referentes al raciovitalismo, y la fenomenología que él conocía por entonces estaba alejada de ese raciovitalismo que finalmente va a tener muchos puntos de encuentro y coincidencia con la Lebenswelt husserliana. "Ortega no se daría cuenta, en cambio, de cómo su propia filosofía coincidía en muchísimos puntos y formulaciones con la fenomenología de Husserl, desarrollada en su tránsito de lo estático a lo genético, desde inicios de los años 20 hasta su muerte" (p. 41). Todavía añade el autor unas líneas adelante lo siguiente: "En varias de las obras husserlianas posteriores a los años 20 , encontramos paralelismos asombrosos entre las consideraciones, temas, ideas, nociones y contenidos husserlianos, y las del propio Ortega" (p. 41). Luego de ello el ensayo se centra en presentar algunos pasajes de las Meditaciones del Quijote en los que sale a relucir la influencia de la fenomenología en esta obra. El autor cita los pasajes en los que Ortega resalta el concepto fenomenológico de escorzo (Abschattung) (p. 44), la suerte de fenomenología de la cultura que se desprende del aparatado dedicado a la "Cultura mediterránea", el que dedica a "Las cosas y su sentido" y aquel pasaje en el que Ortega pone el ejemplo del sendero por donde ve cruzar los mirlos en plena alusión al ejemplo husserliano del mirlo que echa a volar (p. 43). González Di Pierro se detiene también en el análisis de la forma y el contenido del análisis del sonido que presenta Ortega en la obra citada y, sobre todo, y con especial atención, en el tema de la profundidad y la superficie. El autor concluye su ensayo afirmando esto: "Buena parte de la originalidad de la filosofía de Ortega radica precisamente en un desenvolvimiento del ideal que la fenomenología persigue desde el inicio... sin darse cuenta que está, paralelamente a Husserl, llevando a cabo un proyecto que desde los esbozos de la fenomenología se encontraba en el horizonte de las posibilidades de este nuevo filosofar" (p. 47).

Cintia C. Robles y Rubén Sánchez dedican un capítulo al análisis de la "Realidad virtual y fenomenología en el joven Ortega". Como el título indica, se trata de rastrear el vínculo que hay entre el concepto de realidad virtual y su sentido fenomenológico. En algunas de sus obras Javier San Martín ha advertido que el concepto de la virtualidad es una de las mayores aportaciones de Ortega a la fenomenología $y$, en efecto, se trata de una gran contribución que aparece tan tempranamente como 1913. Pero, ¿cuál es el sentido de la realidad virtual en Ortega? En el ensayo se hace una revisión general de la recepción de 
Ortega de la fenomenología y los autores centran su mirada en la dimensión ética de las meditaciones (p. 50) y en la relación de Ortega con la fenomenología (p. 53), para avanzar después en el análisis de la dialéctica de patencia y latencia de las cosas (p. 58) y de superficie y profundidad (p. 60). En este contexto cobra un importante lugar los conceptos de mundo y trasmundo ( $p .59$ ), comenzando por el análisis que hace Ortega de los árboles y el bosque en las Meditaciones del Quijote. Especial énfasis se hace en la crítica al positivismo y al neokantismo que en 1913 Ortega estaba formulando derivado ello de su tercer viaje a Alemania en 1911. En estos ensayos de Ortega puede verse claramente el valor que había asignado a la intuición y cómo a partir de ella quedaban superados tanto el concepto de sensación derivado del positivismo como el concepto de construcción contenido en el neokantismo. En la intuición Ortega habría visto la superación del positivismo y el neokantismo y el valor de la fenomenología. Justamente el concepto de realidad virtual que se expone en este capítulo muestra que el concepto es comprendido por Ortega como realidad virtual, esto es, una realidad vivida que existe a partir y en virtud del sujeto y, al mismo tiempo, una realidad a partir de la cual se gana la seguridad de las cosas. Si bien el concepto no puede sustituir la "carne de las cosas", sí se gana seguridad con él y se accede a la profundidad de las cosas. Por ello el concepto no quiere sustituir la vida espontánea, sólo asegurarla (p. 65).

En el ensayo de José Lasaga Medina sobre "Meditaciones del Quijote en la génesis de la razón vital" se analizan tres cuestiones fundamentales. Primero, qué es y cómo se conciben las Meditaciones del Quijote. Lasaga apuesta por defender que la primera obra de Ortega "contiene la propuesta o el proyecto de una filosofía que está por pensarse" (p. 67). El desencanto de Ortega de la filosofía neokantiana lo llevó en 1911 a su encuentro con la fenomenología de Husserl. El autor resalta el Prólogo de las Meditaciones del Quijote donde aparecen algunos conceptos fundamentales de la obra de Ortega: "salvación", "circunstancia" y "perspectiva" (p. 68) dejando apuntado también que en esta obra "posiblemente" estemos ante "la inspiración más profunda del ethos filosófico que buscaba Ortega para sus meditaciones" (p. 69). Como es sabido, las Meditaciones del Quijote conforman una serie de ensayos y reflexiones sobre la realidad española; Ortega quiere salvar a España de un nihilismo que ha ido creciendo y extendiéndose en la cultura europea (p. 71). Meditaciones del Quijote es una respuesta al reto de Unamuno, quien se ha declarado abiertamente 
"anti-moderno" y Ortega ha decidido responder al reto de Unamuno desde el mismo campo de batalla propuesto por el autor de Del sentimiento trágico de la vida, pero Ortega lo hace centrando su mirada en el "quijotismo del libro". Así pues, en las Meditaciones del Quijote vemos expuestas las líneas fundamentales de una fenomenología de la cultura en la cual Ortega quiere evitar dos extremos, dice Lasaga: por un lado, la idealidad y, por otro, la materialidad ( $p$. 80). El segundo apartado expone a partir de un análisis crítico el impacto que provocó en Ortega el surgimiento de la Gran Guerra de 1914 y, por el mismo tiempo, la decepción de Ortega de la política. Ortega llega a afirmar que "la filosofía si quiere serlo de verdad, debe quedar desvinculada de la política" ( $p$. 82). En al apartado final Lasaga discute cómo Ortega recupera las Meditaciones del Quijote al inicio de la segunda navegación y lo hace mostrando cómo a la altura de 1932 hace una autointerpretación de su primer libro y le confiere "un lugar fundacional" (p. 89). Lasaga concluye afirmando que en las Meditaciones del Quijote estaban ya contenidos todos los elementos de la filosofía de Ortega: "la vida como realidad individual, la "necesidad" de la cultura para trascender de la mera vida animal, los errores del siglo XIX, la quiebra del mito del progreso, la sospecha acerca de la dimensión de lo social, precedente de la caracterización de siglo XX como "rebelión de las masas", el reconocimiento de la subjetividad como limitación de la condición humana y la creciente denuncia de las pretensiones de "objetividad" como subjetivismo -al menos en lo que respecta a los asuntos de la vida humana (p. 92). Pero le habría faltado a Ortega, a juicio de Lasaga, expresar sus ideas sosteniéndolas en "una tesis metafísica" ( $p$. 92).

Por su parte, el ensayo de Roberto Menéndez centra su atención en la traducción de Erlebnis de Ortega para explorar los "Caminos de la razón vital". De acuerdo con Menéndez, el programa que desarrolló Ortega en las Meditaciones del Quijote responde a una "filosofía integradora de amplio contenido práctico" (p. 98). Ortega da un giro al lema de la fenomenología de "ir a las cosas mismas" haciendo un Ilamado de salvación: "salvémonos en las cosas". En la línea de una filosofía de la cultura "Ortega buscará el modo de conjugar la cultura mediterránea de las superficies con la cultura germánica de las profundidades, el tacto con el concepto" (p. 97). Pero, avanzando un poco, ¿qué representó para Ortega la fenomenología? Roberto Menéndez responde afirmando que: "La fenomenología reivindicaba una vuelta a la experiencia concreta, desalojando 
los -ismos que enarbolaban cuestiones parciales y no aspiraban a lograr el sistema" (p. 99). La fenomenología muestra esta nueva sensibilidad que empezaba a surgir en la filosofía del siglo XX. Así, el autor resalta la traducción de Erlebnis por vivencia por parte de Ortega como una de las mayores aportaciones del filósofo español a la fenomenología. "La vivencia es en realidad un momento de la vida; cada momento en que se actualiza la relación de sentido que el sujeto guarda con las cosas y con su circunstancia" (p. 105). Por ello, "la finalidad de su filosofía no es otra que la comprensión de la vida como realidad radical" (p. 105). Así pues, Roberto Menéndez dedica un profundo análisis del fondo y forma de las vivencias bajo el análisis descriptivo de la ejecutividad y la trascendencia, la intimidad y la reflexividad.

El libro cierra con el ensayo de Sandra García Pérez y Javier Echeverría Ezponda en el que se aborda "El problema del conocimiento y la teoría del punto de vista". En este trabajo los autores centran su atención en el problema del conocimiento y siguen una línea de trabajo en la que resaltan cómo la fenomenología dio a Ortega elementos fundamentales que le permitieron acceder al problema. La teoría del punto de vista tiene un sentido fenomenológico, pero lo mismo ocurre con el método de las series de aproximación, mismo al que Ortega ya hacía referencia en las Meditaciones del Quijote. Recordemos que en la intuición Ortega vio la superación de la antigüedad y la modernidad desde un punto de vista epistemológico. Pues bien, Echeverría y García se centran en el problema de la verdad. Recapitulando una frase de Ortega, los autores citan estas palabras: "la fe en la verdad es un hecho radical de la vida humana: si la amputamos queda esta convertida en algo ilusorio y absurdo" (p. 129). Por ser la verdad uno de los problemas que Ortega hizo frente en sus escritos tempranos, la teoría del punto de vista viene a ser de suma importancia. En el artículo se resalta el sentido ético del perspectivismo orteguiano y lo importante que resulta que cada individuo sea "fiel a su punto de vista" (p. 133). Como ya señalaba Ferrater Mora, la filosofía de Ortega es "una perpetua busca de claridad", pero se trata de una claridad necesaria para la vida, es la vida que busca su significación. Para finalizar, el último apartado lo dedican Javier Echeverría y Sandra García al tema de las series de aproximación o series dialécticas. Aquí los autores hacen un puente entre la fenomenología y la filosofía de Ortega, y muestran lo importante que es la intencionalidad de la conciencia de la que ha- 
bla Husserl, ya que esta es interpretada y asumida por Ortega como "vida humana", esto es, como "coexistencia" del hombre con el mundo (p. 144).

Con estos ensayos celebramos el centenario de las Meditaciones del Quijote y exploramos la actualidad de Ortega y de la fenomenología misma que está contenida en su obra. 